\title{
Article
}

\section{The role of trade unions in supporting victims of domestic violence in the workplace}

Wibberley, Gemma, Bennett, Tony, Jones, Carol and Hollinrake, Alison

Available at https://clok.uclan.ac.uk/21893/

Wibberley, Gemma orcid iconORCID: 0000-0002-7827-8227, Bennett, Tony, Jones, Carol and Hollinrake, Alison (2018) The role of trade unions in supporting victims of domestic violence in the workplace. Industrial Relations Journal, 49 (1). pp. 69-85. ISSN 0019-8692

It is advisable to refer to the publisher's version if you intend to cite from the work. http://dx.doi.org/10.1111/irj.12204

For more information about UCLan's research in this area go to http://www.uclan.ac.uk/researchgroups/ and search for <name of research Group>.

For information about Research generally at UCLan please go to http://www.uclan.ac.uk/research/

All outputs in CLoK are protected by Intellectual Property Rights law, including Copyright law. Copyright, IPR and Moral Rights for the works on this site are retained by the individual authors and/or other copyright owners. Terms and conditions for use of this material are defined in the policies page.

\section{CLoK}

Central Lancashire online Knowledge www.clok.uclan.ac.uk

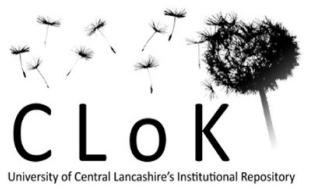


TRIGGER WARNING - This article contains information about domestic abuse/violence

The role of trade unions in supporting victims of domestic violence in the workplace

\begin{abstract}
This article explores the effects that domestic violence has on victims in their workplace and how trade unions respond. Focussing on the experiences of union representatives, the research highlights the support offered to victims, the barriers representatives face, and the under-acknowledged personal impact that these cases can have upon representatives.
\end{abstract}




\section{INTRODUCTION}

In the UK trade unions are involved in highlighting the impact of domestic violence in the workplace, raising awareness of its effects on employees and encouraging employers to put domestic violence policies in place (Elger \& Parker, 2006). At a local level, union representatives have also been actively involved in supporting their members who are experiencing domestic violence. However, this is rarely examined in the literature. This paper will explore the role that trade union representatives have in supporting victims/survivors of domestic violence in the workplace.

The scale and scope of domestic violence has long been recognised in the UK, with at least $27 \%$ of women and $13 \%$ of men suffering from domestic violence during their lifetime (ONS, 2016:75). What is less well documented is the impact of domestic violence on employees and workplaces, although a TUC survey found that $13 \%$ of victims were experiencing domestic violence in the workplace (TUC, 2014:4). Research has shown that this can directly impact on an employee's productivity, absenteeism, and employment prospects (de Jonge, 2016).

Crucially, workplaces can provide valuable support for employees who are experiencing domestic violence (Reeves and O'Leary-Kelly, 2009). This said, fear of disclosing their situation to an employer can make accessing this help problematic (Swanberg et al., 2007). Thus, for many victims, disciplinary sanctions can be a more common first response from 
their employer (Faichnie, 2010), as workplace problems are misinterpreted by managers and HR professionals (EHRC/CIPD, 2013).

It is within this context that the role of unions becomes significant. Unions can collectively negotiate for better support and polices (Baird et al., 2014). They can run awareness raising campaigns, and offer resources for employee representatives and companies to support victims and survivors (Elger and Parker, 2006). Representatives can also support employees on a one-to-one basis, for instance advising them about relevant external services (Foreman, 2006).

Yet, despite the beneficial role employee representatives play in handling workplace domestic violence, there are limited studies in this field. Indeed, domestic violence as a workplace issue is also generally under-researched. Drawing upon a small-scale survey of 18 union representatives this paper will explore employee representatives' experiences of handling domestic violence cases.

This paper highlights key issues within domestic violence, and uses available evidence to demonstrate its impact upon workplaces, employees and unions. It is argued that union representatives can have a crucial role to play in an employee being able to keep their job and access organisational support if they are experiencing domestic violence. However, representatives face challenges in providing that support due to issues of non-disclosure and the lack of understanding and awareness within workplaces. Representatives' capacity is also shaped by the support (or its absence) from other organisational actors and policies. Furthermore, the study reveals that there can be high expectations upon representatives from others and upon themselves, to be able to manage domestic violence cases on the part of their 
member, the victim. This is a role they may not have been trained for, nor have sufficient support for managing in relation to the personal impacts of the cases on themselves.

\section{LITERATURE AND EVIDENCE REVIEW}

\subsection{Domestic violence - isn't this a private matter?}

Domestic violence is often perceived as a private matter (Swanberg et al,. 2012), which takes place within and only affects the 'domestic' realm and, as such, it can be viewed as of little consequence to employers and employee relations. Consequently, domestic violence is rarely acknowledged in UK employment policies, practices or literature. Nevertheless, there is data to suggest that domestic violence costs employers at least $£ 1.9$ billion annually in 'lost economic output' in the UK alone (Walby, 2009). Nor is this isolated to specific sectors or employers; it is estimated that around $10 \%$ of workers in every organisation are experiencing domestic violence at any given time (EHRC, 2010:5).

Furthermore, domestic violence is perpetrated between couples of any gender or sexuality, or by family members and affects all socio-economic groups. Women, however, are substantially more likely to be the victim of domestic violence (Walby et al., 2016), with around double the amount of women experiencing abuse across their lifetime compared to men (ONS, 2016:75). Women are at higher risk of severe abuse or domestic violence homicide, with two women murdered every week by their partner, former partner or lover in the UK; in addition, around two men a month are killed in England and Wales by a current or former partner or lover- although the source does not report the gender of the perpetrator (Roe, 2010:14). 
The impact of domestic violence on the physical, emotional and mental health of victims is well documented (Swanberg et al., 2006; Walby, 2009; Faichnie, 2010). This can manifest itself through a combination of: physical abuse, such as punching and stabbing; sexual abuse, for instance, rape and non-consensual sex acts, and sexual put downs; emotional or psychological abuse such as intimidation, verbal abuse or threats to take the children; financial abuse, where the perpetrator controls the victim's use of money and economic resources, and/or interferes with a victim's access to work, education and training (Refuge/Respect, 2010:11). Experiencing domestic violence has also been associated with increased symptoms of depression and anxiety for both female and male victims; and physical effects such as respiratory, musculoskeletal and cardiovascular conditions (Dillon et al, 2013). Furthermore, Wathen et al. (2016) report that if the domestic violence continues whilst the victim is at work, then this is likely to result in increased negative health effects for the victim.

Unsurprisingly, because of the abuse, victims are likely to have higher absenteeism and reduced performance at work (de Jonge, 2016). Attendance may be low, as perpetrators may try to prevent employees going to or staying at work through physical violence; sleep deprivation; preventing them from leaving the house; destroying work equipment or clothing; threats to victims or others (including children); removing access to transport; contacting and harassing the victim at work in person or via any form of communication (Walby and Allen, 2004; Moe and Bell, 2004, McFerran, 2011; Beecham, 2014; Wathen et al., 2016). These forms of abuse also decrease an employee's performance, as they are unable to concentrate and are suffering from the physical and psychological impacts of the abuse (TUC, 2014). Individuals may leave their jobs either because they are trying to escape the violence and 
have left their partner or at the perpetrator's insistence (Sanders, 2015). Equally, employers may dismiss staff due to declining workplace performance (Swanberg and Logan, 2005).

Perpetrators are highly likely to know an employee's workplace and routine (Jones et al., 2010), and use this knowledge to stalk victims during their commute or enter the workplace or surrounding premises to abuse them (TUC, 2014). This can make an employee vulnerable, even after leaving the abusive relationship. Tiesman et al. (2012) state that the risks are higher when the worker is in a staff car park; entering or exiting work; in an open access or poorly secured workplaces such as hospitals and hairdressers. Co-workers and clients are also at risk from the perpetrator's violence either towards them or because of effects on the victims (TUC, 2014; Gregory et al., 2016).

Nonetheless, it is clear that supportive workplaces can be invaluable for employees. For some their work is a 'safe haven' where they can physically and emotionally escape domestic violence (EHRC/CIPD, 2013; Beecham, 2014). It can also be a place where they can access information about domestic violence services without alerting the perpetrator (Faichnie, 2010; Katula, 2012). Employees may also be provided with assistance from their employers, such as: counselling services; changed hours or work relocation to decrease perpetrators' awareness of their routine; enhanced security measures or paid leave (Forster, 2010; Beecham, 2014). For others, their earnings can enable them to escape from an abusive relationship (TUC, 2014), making it important that they are able to continue to work.

\subsection{Trade union interventions in domestic violence}


In the UK, trade unions have been involved for some time in supporting members experiencing domestic violence and in demonstrating its effects upon the workplace. UNISON, the GMB and UNITE all have long-standing policies for countering domestic violence (McBride, 2000; Elger and Parker, 2006). More recently, the public sector and civil service union, PCS, launched its ongoing domestic violence campaign at its national women's forum (PCS, 2009). Similarly, retail union, USDAW, locates its domestic violence policy clearly within its strategy for greater women's equality (USDAW 2016).

Unions were involved in implementing the first workplace policy on domestic violence at Edinburgh Council (Mackay, 1996). Since then, trade union activities internationally have included: negotiating for domestic violence policies (Parker and Elger, 2006; Nicholson et al., 2017); raising awareness within the unions, workplaces and the wider community (Mackay, 1996; EHRC, 2009); providing training (Parker and Elger,2006; Damanin and Kun, 2011); working collaboratively with a variety of stakeholders, especially domestic violence specialists (Beecham, 2009); campaigning to improve legislation and services (EHRC, 2009); providing information about services and resources available to victims (Foreman, 2006); creating resources for workplace campaigns (Parker and Elger,2006); supporting individual victims, practically and emotionally (Beecham, 2009); creating resources to support employers (Atterbury, 1998), and encouraging them to offer flexible working arrangements to those experiencing domestic violence (Damanin and Kun, 2011). In the broader role of promoting equality and diversity in the workplace, it is of note that recently unions in the UK are developing a network of specialised equality representatives to support their local branches (Moore and Wright, 2012). 
For these reasons, charities and expert organisations recommend that trade unions are involved in developing organisational policies and procedures for responding to domestic violence in the workplace (Refuge/ Respect, 2010). Perhaps most importantly, evidence suggests that positive support from union representatives when victims face dismissal because of the impact of domestic violence, can significantly reduce the chances of victims losing their jobs (Forster, 2010).

\subsection{Barriers to trade union intervention}

Despite the multiple benefits in unions addressing domestic violence, there are also considerable barriers to their effective support for members. A key problem is that domestic violence may not be seen as an issue by unions (Wagner, 2003; Elger and Parker, 2006) or their members, even for those experiencing abuse (Parker and Elger, 2006; Beecham, 2009). Unions may also face a dilemma between supporting members who are perpetrators and wanting to challenge domestic violence (Wagner, 2003).

Although the TUC has long recognised the need to equip activists with a greater understanding of domestic violence $(2002,2013)$, a further barrier is that not all representatives have the skills or knowledge to support members experiencing domestic violence (Parker and Elger, 2006, Foreman, 2006). Additionally, it is suggested that not all unions or representatives offer the same standard of response (Faichnie, 2010). For instance, some unions have specific policies on addressing domestic violence, while others have subsumed the issue within the broader area of "the negotiation of workplace policies on bullying, sexual harassment and violence at work' (Parker and Elger, 2006: 24), an approach which critics feel loses focus on the issue (ibid.). There can also be difficulties in encouraging 
line managers and organisations to accept and address domestic violence as a workplace issue (Damanin and Kun, 2011; Nicholson et al. 2017).

The wider issue of victims' understandable reluctance to disclose their situation, also impacts on them accessing any workplace assistance that is available, as without revealing their problems they may be ineligible for or not provided with support. Victims are often initially afraid to talk about the abuse for fear that it may make the situation worse, that they will not be believed, because of a lack of trust or confidentiality, and not wanting to be labelled as 'abused' (Berry et al., 2014; O’Doherty, et al., 2016). In the workplace there are also additional fears that disclosure will destroy the positive work image they have created, and be detrimental to their career (Swanberg and Logan, 2005; Faichnie, 2010). Where disclosure does occur at work this is most commonly informally to a co-worker (Swanberg et al, 2006) and happens because the victim needs emotional support and someone to talk to about their situation (Reeves \& O'Leary-Kelly, 2009; 89; Swanberg et al, 2006; 569); or because of visible injuries, or the abuser directly intruding into the workplace (Swanberg et al, 2006: $308 ; 570)$.

Victims may also be reluctant to disclose to a union representative for various reasons. Unions are not necessarily perceived to be a 'natural' source of support and information about domestic violence (TUC, 2014). Further, victims may not consider that their representative would be willing and/or able to support them (Parker and Elger, 2006) or may be more reluctant to discuss the situation if the representative is male (Beecham, 2009). In addition, victims may not feel able to afford trade union fees, particularly if suffering economic abuse (Beecham, 2009). It is therefore unsurprising that disclosure is rare at work (Samuel et al., 2011; O’Doherty et al., 2016). 
Crucially, domestic violence may only come to light when an employee faces disciplinary action for their high absenteeism or inability to meet performance targets (McFerran et al., 2013). Managers may have neither the capacity, capability nor awareness of how to best support staff, and it is rare for organisations to have specific domestic violence policies (Parker and Elger, 2006). Even workplaces that provide support for clients suffering from domestic violence, such as hospitals, rarely recognise the need to also provide this support for their staff (Katula, 2012). Many employers thus still seem unaware of the business case, and their moral and legal obligations to protect their staff (Walby, 2009; Samuel et al., 2011; de Jonge, 2016), increasing the challenge for unions to support a victim of abuse.

Despite their good work, further improvements for trade unions have been recommended by commentators to also: provide more training and resources for representatives (Atterbury, 1998;Parker and Elger,2006); work more closely with specialists(ILO, 2013); have experts in the union that representatives can call on for support (Parker and Elger,2006); increase the number of female representatives (Beecham, 2009); raise awareness within unions and organisations about domestic violence (ILO, 2013); and negotiate for effective workplace policies and training (EHRC, 2011).

\subsection{Vicarious trauma}

An issue that seems particularly under-researched is the effect of handling domestic violence cases upon representatives. However, research undertaken on the impact such work can have on professionals assisting victims of abuse, such as counsellors or support workers, has recognised that they are at high risk of experiencing 'vicarious trauma' by being exposed to 
cases of domestic violence (Iliffe and Steed, 2000; Slattery and Goodman, 2009). This trauma can have negative effects on the professionals' physical and psychological well-being. Gregory's (2017) research into the impacts of providing informal support for victims is also relevant here, particularly as colleagues are recognised as a group of 'informal supporters'. She suggests that co-workers witnessing or being told about the domestic violence can suffer from post-traumatic stress disorder (PTSD) and have similar negative impacts on their physical and mental health (Gregory et al.,2016). Having personal experience of domestic violence may increase vicarious trauma, as may higher levels of exposure in terms of the number of cases handled or closeness of the representative to the victim (Slattery and Goodman, 2009; Gregory et al.,2016). Both professionals and colleagues may also be placed at risk of harm from the perpetrator, thus increasing their anxiety (Iliffe and Steed, 2000; Gregory 2017).

Although professionals were aware of the boundaries of their role, they also reported taking on too much responsibility for victim's welfare, because of the difficulty to be detached, and fears for the victim (Iliffe and Steed, 2000). There was also a high risk of burnout if professionals had a high case load, were isolated and lacked training specifically on domestic violence (Iliffe and Steed, 2000).Slattery and Goodman (2009) believed that vicarious trauma was less likely if professionals had the following 'protective factors': strong social support at work; good clinical supervision; a positive relationship with their supervisor, and an 'empowering' workplace environment with shared decision-making and power rather than traditional hierarchical power relations.

Professionals wanted more support from their organisation to help them handle the impact of their work. This included providing: practical safety resources; more peer support and 
debriefing across teams of professionals, so that trauma can be shared more evenly and that there is greater understanding of issues; and help with balancing competing tensions of client confidentiality and risk (Iliffe and Steed, 2000). Professionals also reported feeling powerlessness to protect victims or to make other systems (for instance the law) work more effectively for them.

In summary, there is limited academic literature from the UK on the role of trade unions in addressing the effects of domestic violence in the workplace, and the union representatives who are in the frontline in potentially delivering support to victims. This paper focuses on those representatives' experiences, the barriers they face and the impact on their own wellbeing.

\section{METHOD}

The aim of this research was to explore the experiences of union representatives in responding to cases of domestic violence at work. With support from a regional TUC Women's Committee, unions from a cross-section of industrial sectors agreed to participate. The Women's Committee was chosen because it was known that these groups have specific interest in domestic violence, and whilst abuse effects everyone it is recognised as a gendered issue. 18 semi-structured interviews were completed with full-time and lay officers. Through purposively sampling the Women's Committee and using snowball sampling to identify additional respondents, a cohort of 17 female participants were interviewed. The gender imbalance of respondents is not unexpected because of the involvement of the TUC Women's Committee. However, men were not excluded from participating and one male also volunteered for the study via the snowballing approach. Respondents came from diverse 
unions and sectors, including: secondary, further and higher education, communications, transport, health, local government, the civil service and retail. All participants, their unions and the organisations they represent have been anonymised for confidentiality. To further protect participants, and the cases they discussed, no personal characteristics are presented. However, in terms of their roles in the union, ten of the interviewees were branch officers, with three of those interviewed also holding the post of equality officer. In terms of other activists, three union representatives were also interviewed as was one equality representative. The sample was further made up of one lay national officer and three full-time regional officers. It is of note that almost half of the lay activists also held lay roles at regional or national level of the movement.

The interviews were semi-structured, recorded and fully transcribed and all the researchers shared fieldwork responsibilities. Interviews lasted an hour on average and were conducted either face-to-face or via telephone at the participant's request. Participants were given full information about the project before the interview, and full ethical approval was granted by the University. It must be acknowledged that most of the domestic violence referred to by union representatives was experienced by female employees; however, there were a few cases experienced by male employees. A third of the respondents also voluntarily disclosed that they had themselves been victims of domestic violence.

It is important to note the limitations of this research, in that it reflects only the perspectives of trade union representatives. Nonetheless, we agree with Gregory (2017) that whilst the voices of victims and survivors must remain central to debates around domestic violence, there is a need to also understand the experiences of their supporters to better understand the key issues and the assistance provided. Equally, as participants in this study reveal, 
representatives may have also experienced abuse themselves; therefore, the boundaries between survivor and representative may be blurred. It was also a small study, with voluntary participants who were more likely to participate because of previous cases of members experiencing domestic violence, and potentially with experiences in their own personal lives. Nevertheless, due to the dearth of studies in this field and the importance of the topic it seems necessary to highlight our results.

Utilising template analysis (King 2004), interview transcripts were thematically analysed in order to explore key concepts and dominant issues. This process entailed the construction of an initial template, whereby early categorisation could be made based on the initial questions put to the respondents. The key areas of enquiry covered were: the organisational and union responses to domestic violence; the respondent's role in supporting victims of such violence; their preparedness for this role; the challenges they faced; and the roles played by other organisational actors, such as line managers and HR.

These categories formed the top-level codes. The template analysis then allowed additional themes to be developed. For instance, initial data analysis revealed an emotional pressure experienced by the representatives not covered by the original template. A new code was therefore created with subsequent sub-codes that captured the specifics of this pressure in terms of, for example, levels of empathy, representatives' own coping strategies and the degree and nature of support received from their union.

\section{FINDINGS}

\subsection{The Impact of abuse}


Respondents were clear that domestic violence can negatively impact upon an employee's attendance and performance. They gave examples of injury and other tactics, such as the perpetrator stealing an employee's work uniform, as reasons why absenteeism and timekeeping became problems. Performance was often reported to decline because of the stress and fear from the abuse. Employee's performance appeared likely to be further affected if perpetrators continued to abuse them during working hours and / or on work premises; for instance, by contacting staff via telephone and email, coming into the workplace or car park, or pursuing them on their commute. Perpetrators are often acutely aware of the employee's work routine and work is often a place where partners stalk victims, during or even after leaving an abusive relationship:

'had their partner turn up and smash their car...in the work car park... having to take those kind of phone calls in work... having to rush out of work to take phone calls...that got her into the place where she was leaving work before she should have left it and she was leaving pieces of work unfinished and so forth. It was a contributory factor that she was living in a violent situation and fear' (Representative. 3)

Perpetrator actions, such as above, place the employee at substantial risk. Additionally, it raises concerns about the health and safety of co-workers and clients. Yet, despite the risks to individual employees and the wider workplace, a number of the interviewees reported that their employers continued to characterise it as a 'private matter'. Of even more concern, victims could face disciplinary action or even dismissal because of the impact of domestic violence upon their work. It was in this context that the respondents revealed their views and experiences of supporting members who were victims of domestic violence. 


\subsection{The role of the union and union representatives}

In these situations, respondents felt it important for trade unions to address domestic violence. Many of the unions represented in the research appear to have a very thorough approach with advice, booklets, and web-based material, including templates for domestic violence policies to use with employers and practical guides for representatives. However, interviewees were often concerned that more needed to be done, and many gave examples of how they were trying to raise awareness within their workplace and liaising with national and local domestic violence organisations. For many of the interviewees this was an important activity that supplemented both national union action and specific employer-led initiatives, where these existed.

For individual representatives, their role in domestic violence cases is primarily to advise and direct members to external agencies and to support them in relation to any work specific issues that arose. Responses ranged, therefore, from one case where the representative arranged financial support from the union for the member and her children, to cases where the representatives were working with external agencies such as the police or refuge services. Representatives were also able to work both formally and informally with managers and HR to put in place bespoke workplace support such as changed work patterns, additional security, monitoring communications, redeployment and financial assistance. This support could be crucial in enabling an employee to remain in work whilst trying to deal with the domestic violence, and potentially leave the perpetrator:

'[We] arrange stuff within what's manageable for them, for a period of time, with reviews...it might be that they need different times of working. Or it might be that they need lesser hours for a period of time. Or it might be that they need a phased return to work' (Representative1) 
However, representatives could also experience difficulties in persuading employers that domestic violence is a workplace issue. Several interviewees noted that there continued to be a perception that this was a 'private' matter and that employees' problems should be kept at home. Respondents explained it was often valuable to detail the 'business case' of addressing domestic violence to employers. A reflection, perhaps, of a more pragmatic approach necessary by representatives when the balance of power remains generally with the employer. For instance, highlighting the duty of care organisations have to look after their staff, or explaining the health and safety implications of domestic violence on work premises, and in relation to employees, colleagues and clients. The relatively low-cost actions, such as changing contact details, enabling flexible working or increasing security arrangements that could increase performance, attendance, morale and retention could also be useful leverage for representatives:

\footnotetext{
'It took quite some persuading to be honest because their attitude and behaviour was it's not a workplace issue. I had to point out to them that the workplace was the only place he [perpetrator] knew he could get to her. He knew her working patterns, he knew, the entrances and exits to the building. [He] would ring her and annoy her at work. And I said [to the manager] obviously that would impact on her being able to perform and that's your responsibility but your duty of care as well and her safety, which actually started to change the mind-set, to get them then to move her to a different floor, and then to put these adjustments in place in terms of flexibility in terms of the hours that she was to work' (Representative 16).
}

An additional challenge for all stakeholders in domestic violence cases is that, as has been noted above, victims are often very reluctant to disclose the abuse, particularly in the workplace. For many victims, domestic violence continues to carry a stigma and it remains a 
largely hidden problem. The majority of the union representatives interviewed were aware that getting victims to tell them or to tell managers about the violence was a huge hurdle:

'The problem is because it is, to me, kept underground, it's very hard to get somebody to have confidence in you...because a lot of people don't want to talk about it...but if they know you're only there protecting [them at] work, they might come forward and confide because that's what's causing them issues at work' (Representative 12).

The concerns that shape victims' reluctance to disclose centred around; shame, embarrassment, fears about confidentiality, and the belief that being a victim of violence would in some way reflect badly on them and alter how co-workers and managers saw them. This is reflected in the comments of one representative, who had herself experienced domestic violence:

'I need to be seen as a strong independent woman who can make effective changes and if I let this happen to me, I'm not going to be seen as strong and capable' (Representative 9).

Several representatives commented that for some victims, not only might they fail to realise that the union could provide them with support, but they might also be reluctant to disclose to their union representative. Interviewees noted that some people were concerned that disclosure would result in others knowing about their situation. Some representatives felt that gender might be an issue, suggesting that both male and female members may be more likely to disclose to female representatives. Others highlighted that they had a 'mixed team' of men and women representatives in their branch who had supported both female and male victims of domestic violence. A surprising issue was that some members apparently feared that disclosure would lead to unwanted intervention: 


\footnotetext{
' The thing [they worry about that] if they tell the rep they are going to act on it... and I think us as representatives have to give the message quite clear, that we will only act, we will only do something when they want us to' (Representative 10).
}

It can be very difficult for trade union representatives to recognise domestic violence as an underlying issue for a member, as one interviewee noted:

'If someone is just generally down and anxious and stressed and is off sick a lot you wouldn't automatically put that with domestic violence because you would not have that link' (Representative 6).

Some representatives could become aware in a dramatic way, as one representative explained they were 'just chatting' to a member who suddenly became 'hysterical and said I've got to tell you this, I've got to tell you this, And she just pulled up her jumper and I just, I was just like oh my god. And she was bruised, her torso and then she just was inconsolable' (Representative 16). More often representatives described a more complex process where the situation is revealed more incrementally:

'I find then it comes to the bit where they are having problems that is the bit, they have to come to us, they have to start telling us a little bit of information because you have to go, "I need the full story. I need to back you up, I need to give reasons why you are struggling and try and put things in place to help you. But I can't do that if I don't know what is going on". And they may tell you a couple of things and once they tell you a couple of things you might get a little bit more of the story'(Representative 7).

When a representative becomes aware that domestic violence is a factor, this presents its own challenges since they have to respect the confidentiality of the union member and many employees do not want their managers to be told. Yet to arrange internal support and access 
domestic violence polices (if available) disclosure may be required. Perhaps unsurprisingly, therefore, victims often only disclose when they reach a point of crisis in their lives and/or in the workplace:

\footnotetext{
'Her husband had abused her, physically and sexually, and her two children...I was phoned when she was in absolute dire straits. He'd come in and he'd wrecked all the furniture, thrown it out... She sold her house and downsized because she had nothing at all. She had no money. She was eating flour and water' (Representative 1).
}

To effectively support members, representatives felt they needed awareness of: external support services; organisational processes; and the support available internally from unions and organisations. Respondents noted that this information is not always readily available, despite the resources some trade union provided. Therefore, they may be relying on personal knowledge or life experiences:

'Effectively we never have any training, you just go off what your gut feeling is, don't you and you do it with a lot of different issues' (Representative 12).

It appeared that domestic violence training for union representatives tended to be variable. The TUC have developed training materials and courses, as have several individual unions. Others had also had training related to a job role (e.g. as housing officers or social workers). Nevertheless, awareness of and access to training seemed variable between respondents, even where they were from the same union. In some cases, this was due to the difficulty of getting time off work to attend. Therefore, most interviewees were responding to members experiencing domestic violence without any previous training. 


\subsection{The Impact on Representatives}

The impact on representatives in handling such cases is particularly under-examined, yet it can have a considerable effect on them. Many of the interviewees were clear that their role was to support and advise members who were experiencing domestic violence and not to become personally involved. Interviewees reiterated that their role was not to act as a counsellor but to point the member in the direction of those professionals who could help. It was necessary, it was suggested, to draw a boundary around what the union representative could be expected to offer as support and not to overstep this into trying to solve problems for the employee:

\footnotetext{
'You can get too personally involved, but you've got to be quite professional about it. In my eyes it's about highlighting it, helping them giving them what they need but then taking a step back' (Representative 11).
}

Nevertheless, although representatives appreciated that they needed to draw a boundary around the support they should give in cases of domestic violence, this was not as straightforward in practise: 'it can be very upsetting, quite often can be very upsetting and also you do worry for people who are going through that experience' (Representative 3). It could also be hard for a representative to 'not to say to this woman, come to my house, bring the kids, I'll put them up' (Representative13). In some situations the representatives felt that staff needed substantial support: for example, one rang the union member 'every day' for several months to check they were safe. Yet providing support, especially in the most challenging cases, could have unrecognised substantial impacts upon the representatives themselves: 
I don't think it's always thought about as how much that takes out of you. And I've had some pretty horrendous cases lately... [I] say we're like a battery. And my battery was depleted. ...If I don't recharge my batteries I can't carry on giving to you...So I do think there's an aspect of coping strategies that are needed by trade union officers, not just victims and perpetrators' (Representative 17).

Other respondents also commented that they needed additional support themselves at times. Some were able to discuss their experiences of supporting cases at branch meetings and draw upon informal support from other representatives: 'I think the union team is a real kind of strength, a network of strength and people understand that, also understand what you've [experienced]' (Representative 9).

However, other respondents felt more was needed to support the emotional impact that domestic violence cases could have upon representatives. Reflecting on the role that they played supporting union members who were victims of domestic violence one interviewee commented:

'But I do think the thing that isn't thought about is how do the trade union officers deal with it. Counsellors all have mentors; anyone who's a proper counsellor has someone to talk to. Trade union officers, I've gone home at night and cried at some cases right and I've had to find my own strength' (Representative4).

It is therefore also possible that trade union representatives may be at danger of vicarious trauma. Researchers have found that such experiences can have serious negative impacts on the mental and physical health of those who support victims of domestic violence, albeit in the context of a professional or agency support role. It should also be noted that other professionals are likely to have processes such as debriefing or supervisions to help them 
manage their cases and own wellbeing, but representatives are unlikely to have this support potentially putting them more at risk. A representative who had been dealing with a particularly challenging case commented:

'I just felt compelled that I had to support this individual because of what she'd shared. I then became sort of worrying the whole time about her even in my own personal life. It had started to impact upon me because I just couldn't believe what I saw and heard' (Representative 6)

Union representatives' exposure is likely to be less than those supporting victims full time, therefore on one hand reducing potential harm. This said, representatives may not have chosen (or expected) to undertake domestic violence cases in their role, unlike a domestic violence professional. Therefore, the representative may have personal experience that could be inadvertently triggered; as one representative commented when reflecting on a colleague:

'[She] decided not to do it anymore. She stayed a rep but she didn't want to do the domestic violence thing because it kind of got into a little bit...of what had happened with her mum and dad' (Representative 10).

It should also be noted that representatives can be in jeopardy from retaliation from perpetrators if their role becomes known to them. In one case the union representative felt they had to devise a 'check in/ check out' plan with their branch secretary if they were out of the office with the member they were supporting, and to have a set time when they were due back, so that action could be taken if necessary.

\section{DISCUSSION}


In summary, this study builds upon previous research (Elger and Parker, 2006; Foreman, 2006; ILO, 2013) demonstrating that union representatives can have a crucial role to play in an employee being able to keep their job and access organisational support if experiencing domestic violence. The paper also highlights the challenges that representatives face in providing that support, and the impact it has upon them personally. Although the TUC's (2014) research suggests that victims of domestic violence do not often look to their union for advice, the testimony from the interviewees in this research shows that where this support is sought union representatives can be heavily involved in supporting members.

In the limited evidence on domestic violence and employment relations, it is recognised that the workplace may be a high-risk site because perpetrators are typically aware of the victim's location and routine at work (Moe and Bell, 2004; Tiesman et al., 2012). This was unfortunately replicated in this study, with victims experiencing domestic violence during working hours and at the worksite. The resulting impact of the abuse on the employee's workplace behaviour could lead to disciplinary action. Thus, reinforcing concerns that at a time when employees are likely to require support from their company, they are actually at risk of losing their job (Atterbury, 1998; McFerran et al., 2013).

The findings reveal that many unions have a wide range of materials to raise awareness and support representatives in handling domestic violence cases in the workplace. The representative's own role is to support, advise and direct members to professionals. Representatives are often first involved when a member faces a crisis. However, the lack of employee disclosure of domestic violence appeared to be a substantial barrier for representatives. Although it is unsurprising that victims do not want to discuss their abuse at work: in that there is substantial evidence of victims' fears that disclosure will have a 
negative impact upon their wellbeing and careers (Swanberg and Logan, 2005; Beecham, 2009; Faichnie, 2010; Berry et al., 2014; O’Doherty et al., 2016). Previous studies suggest that the masculine nature of trade unions may be off putting to some victims (Beecham, 2009), and although this was not a central issue in the study, this view was also expressed by a few of respondents. However, representatives also described ways in which they were attempting to mitigate any potentially negative impact on disclosure. For instance, having 'mixed team' of men and women representatives who had supported both female and male victims of domestic violence. Interestingly, findings from this study also suggest that the proactive role of unions may be a double-edged sword if victims believe that following disclosure representatives will intervene without their permission and that this will have detrimental consequences on their employment. Overall, this indicates that there are considerable barriers for an employee to overcome to feel safe to disclose at work.

Even if companies are fully aware of the victim's situation, representatives may still face difficulties in persuading employers that domestic violence is a workplace issue (Elger and Parker, 2006; Beecham, 2009) Despite the overwhelming evidence to the contrary (Walby, 2009; EHRC, 2010; TUC, 2014), domestic violence is still perceived as a 'private' matter by some managers (Swanberg et al,. 2012; de Jonge 2016). In situations such as these, the research revealed that representatives found it important to convince employers of the 'business case', for instance reminding managers of their 'duty of care'; the health and safety implications for staff, clients and victims; cost savings of taking action; or impact upon reputation. Respondents noted that this leverage could be effective in persuading companies to be more supportive towards victims. 
A further barrier for representatives is that although they can reportedly access a range of specialist training, in practice most respondents find themselves involved in supporting a member experiencing domestic violence without having had formal training. This can make responding to cases challenging, as Iliffe and Steed (2000) commented on for other professionals handling domestic violence cases. Furthermore, this suggests that previous calls to increase training and resources for representatives are not, as yet, being answered (Atterbury, 1998; Parker and Elger, 2006).

When involved in a case, official union advice for representatives is to point an employee towards specialist agencies who can assist them, and it is clear that this is taken note of by those spoken to in the study. However, often respondents did devote considerable time to supporting their members and this can impact upon representatives in quite fundamental ways. There is a lack of evidence on the impact of handling domestic violence cases upon representatives; however, drawing upon studies of others supporting victims worrying trends emerge. It appears vicarious trauma can be a problem for those supporting victims of domestic violence, because of their exposure to the abuse, either through disclosure, witnessing events or risk of harm from perpetrators (Iliffe and Steed, 2000; Slattery and Goodman, 2009; Gregory et al., 2016; Gregory, 2017). It is arguable that trade union representatives are at similar risks themselves.

Although several representatives remarked in the research that they were not counsellors, this is a role that they seem to play in many cases. Not only do they at times go beyond support in the workplace, the situations with which they deal can be very difficult to leave behind even when the case is resolved. Iliffe and Steed (2000) found that other professionals have also reported the difficulties of maintaining these boundaries because of fears for the victim and 
the impracticality of detachment. Unsurprisingly, supporters often suffer from physical and psychological health consequences as a result (Iliffe and Steed, 2000; Slattery and Goodman, 2009; Gregory et al., 2016; Gregory, 2017). The impact these cases have on representatives needs to be more closely assessed by their unions so support for them can be put in place. Representatives themselves felt more assistance from their union would be beneficial, such as debriefing and supervisions. Crucially, these 'protective factors' have been recognised as vital in enabling other professionals to cope with the pressures of these cases, and without them it was noted they were at a higher risk of personal harm (Slattery and Goodman, 2009).

It is also important to note that unlike other professionals who support victims, representatives may not have been aware in advance that this type of support could form part of their role. Therefore, as the study reveals they may find it too distressing to continue, particularly if they have experienced domestic violence personally. As Slattery and Goodman (2009) highlight this may be stressful even for professionals who have chosen to work in this field. A union resource that could potentially support representatives is the 'equality representative', their role is specifically to provide a source of specialist support on equality issues to other representatives and members (Moore and Wright 2012). Overall, however, the role of the equality rep was not an issue that figured much in the interviews. Significantly, with the exception of studies on the union learning representative (Stuartet al., 2013), there is little current research on the nature, or lack, of support for union representatives in general.

\section{CONCLUSION}

Overall, the study posits that unions and their representatives have an important role to play in supporting victims of domestic violence, individually and collectively. Nevertheless, the findings also demonstrate that it is a difficult role, and by focussing on the representatives' 
experiences the paper illuminates the challenges they face to assist their members and to cope personally with that role.

The paper also raises practical implications. Workplaces can be key sources of information and support for those experiencing domestic violence. There is a clear business case for employers, as outlined throughout, to recognise domestic violence as a workplace issue. More informed and sensitively executed policies and practices to address domestic violence can benefit both victims and employers. The study suggests that, like the employer, the union must also ensure that as broad a range as possible of its representatives have been equipped though training with the understanding and knowledge to support employees. However, it is unlikely that policy and training alone will be effective (Reeves \& O'Leary-Kelly, 2009). Union representatives thus have a crucial role to play in opening up debates within the work context about domestic violence, to reduce the stigma and reluctance to disclose that make accessing the support more difficult. If domestic violence is openly discussed as workplace issue and it is clear to employees who do disclose what they can expect in response, then it is more likely that they will feel able to seek support (Swanberg et al, 2007). Equally, to provide the crucial support they do, union representatives need additional physical support, in terms of protection from perpetrators and emotional support, like that given to professionals in the domestic violence field. Vicarious trauma should not be a barrier to the vital work that the representatives do in supporting their members. 


\section{References}

Atterbury, J. (1998), 'Employment protection and domestic violence: Addressing abuse in the labor grievance process', Journal of Dispute Resolution, 2, 3, 165-182.

Baird, M., L. McFerran and I. Wright (2014), 'An equality bargaining breakthrough: Paid domestic violence leave', Journal of Industrial Relations, 56, 2, 190-207.

Beecham, D. (2009), The Impact of Intimate Partner Abuse on Women's Experiences of the Workplace: A Qualitative Study. Unpublished thesis, (Warwick University).

Beecham, D. (2014), 'An exploration of the role of employment as a coping resource for women experiencing intimate partner abuse', Violence and Victims, 29, 4, 594-606.

Berry, V., N. Stanley, L. Radford, M. McCarry and C. Larkins (2014), Building Effective Responses: An Independent Review of Violence against Women, Domestic Abuse and Sexual Violence Services in Wales. (Cardiff: Welsh Government Social Research).

de Jonge, A. (2016), 'Corporate Social Responsibility Through a Feminist Lens: Domestic Violence and the Workplace in the 21st Century', Journal of Business Ethics, Online early cite doi:10.1007/s10551-015-3010-9.

Damanin, L. and Kun, J. (2011), Family violence is a workplace issue, (Australian Services Union).

Dillon, G., Hussian, R., Loxton, D, and Rahman, S., (2013), 'Mental and Physical Health and Intimate Partner Violence against Women: A Review of the Literature', International Journal of Family Medicine, 2013, 1-15.

EHRC (2009), Better Public Services: Breaking the Silence on Violence against Women (EHRC).

EHRC (2010), Domestic Abuse is Your Business: Employers Campaign Pack (EHRC). EHRC (2011), Domestic abuse is your business: trade union campaign, (EHRC). 
EHRC/ CIPD (2013), Managing and Supporting Employees Experiencing Domestic Abuse, (EHRC).

Elger, T. and A. Parker (2006), 'Union Policies to Combat Domestic Violence: An Analysis of the Widening and Reframing of Union Agendas', CCLS Working Paper 23 (Warwick University).

Faichnie, C. (2010), “Work was an Escape for Me" - The Impact of Domestic Abuse on Employment, The Views of Women supported by the Domestic Abuse: Women's Employment Support Project, (DAWES).

Foreman, A. (2006), Domestic Abuse and the Workplace: A Report Looking at the Impact of Domestic Abuse on Women's Employment, (Greater Manchester Employment Rights Advice Service).

Forster, S. (2010), Evaluation of Domestic Abuse: Women's Employment Support (DAWES) Project, Report on Evaluation Findings, (DAWES).

Gregory, A., E. Williamson and G. Feder, (2016), 'The Impact on Informal Supporters of Domestic Violence Survivors: A Systematic Literature Review', Trauma, Violence, \& Abuse, Online early cite doi:10.1177/1524838016641919.

Gregory, A. (2017), 'The edge to him was really, really nasty': abusive tactics used against informal supporters of domestic violence survivors', Journal of Gender-Based Violence, 1,1, 61-77.

Iliffe, G. and L. Steed (2000), 'Exploring the Counselor's Experience of Working With Perpetrators and Survivors of Domestic Violence', Journal of Interpersonal Violence, $15,393-412$.

ILO (2013), Commission on the Status of Women 57th Session, Australia/ILO Side Event on the Impact of Domestic Violence in the Workplace (ILO). 
Jones, A., J. Bretherton R. Bowles and K. Croucher (2010), The effectiveness of schemes to enable households at risk of domestic violence to stay in their own homes, (University of York).

Katula, S. (2012), 'Creating a Safe Haven for Employees Who Are Victims of Domestic Violence', Nursing Forum, 47, 4, 217-225.

King, N. (2004), 'Using Templates in the Thematic Analysis of Text', in G. Cassell and G. Symon (eds.), Essential Guide to Qualitative Methods in Organizational Research (London: Sage).

Mackay, F. (1996), 'The Zero Tolerance Campaign: Setting the Agenda' in Lovenduski, J. \& P. Norris (eds.), Women in Politics (Oxford University Press, Oxford).

McBride, A. (2000) 'Promoting representation of women within UNISON' in Terry, M. (ed.) Redefining public sector unions: UNISON and the future of trade unions, (Routledge, London).

McFerran, L. (2011), Safe at Home, Safe at Work? National Domestic Violence and the Workplace Survey, (Australia: Centre for Gender Related Violence Studies UNSW).

McFerran, L., N. Cortis, and T. Trijbetz (2013), Domestic and Family Violence Clauses in your workplace: Implementation and good practice, (University of New South Wales).

Moe, A. \& M. Bell (2004), 'Abject economics: The effects of battering and violence on women's work and employability', Violence Against Women, 10, 1, 29-55.

Moore, S. and T. Wright (2012), 'Shifting models of equality? Union Equality Reps in the public services', Industrial Relations Journal, 43:5, 433-447

Nicholson, D., A. Pekarek, and P.Gahan (2017), 'Unions and collective bargaining in Australia in 2016',Journal of Industrial Relations, Online early cite doi:10.1177/0022185617697760. 
O’Doherty, L., A. Taft, R. McNair and K. Hegarty (2016), 'Fractured Identity in the Context of Intimate Partner Violence: Barriers to and Opportunities for Seeking Help in Health Settings', Violence Against Women, 22, 2, 225- 248.

ONS (2016) Focus on Violent Crime and Sexual Offences: Year ending March 2015 (ONS).

PCS (2009) 'You are not alone'http://www.pcs.org.uk/news/standing-together-againstdomestic-violence accessed 18/09/17.

Parker, A. and T. Elger (2004), Combating Domestic Violence: A Role for Workplace Union Organisation? CCLS Working Paper 22, (Warwick University).

Reeves, C. and A. O'Leary-Kelly (2009), Study of the Effects of Intimate Partner Violence on the Workplace (University of Arkansas).

Refuge/ Respect (2010), Domestic Violence Resource Manual for Employers, second edition (Respect).

Roe S. (2010) Homicides, Firearm Offences and Intimate Violence 2008/09, in Supplementary Volume 2 to Crime in England and Wales 2008/09, Kevin Smith (Ed.), Home Office Report.

Sanders, C. (2015), 'Economic Abuse in the Lives of Women Abused by an Intimate Partner: A Qualitative Study', Violence Against Women, 21, 3-29.

Samuel, L., C. Tudor, M. Weinstein, H. Moss, and N. Glass (2011), 'Employers’ perceptions of intimate partner violence among a diverse workforce', Safety and Health at Work, 2,3, 250-259.

Slattery, S. and L. Goodman (2009), 'Secondary Traumatic Stress Among Domestic Violence Advocates: Workplace Risk and Protective Factors'Violence Against Women. 15, 11, $1358-1379$. 
Stuart, M., Cutter, J., Cook, H. and Winderton, J. (2013) Who stands to gain from union-led learning in Britain? Evidence from surveys of learners, union officers and employers, Economic and Industrial Democracy, Vol. 34, No. 2, pp. 227-246.

Swanberg, J., \& T. Logan (2005), 'Domestic violence and employment: A qualitative study', Journal of Occupational Health Psychology, 10, 1, 3-17.

Swanberg, J., C. Macke and T. Logan (2006), 'Intimate partner violence, women and work: Coping on the job', Violence and Victims, 21, 5, 561-578.

Swanberg, J., C. Macke and T. Logan (2007),'Working women making it work. Intimate partner violence, employment, and workplace support', Journal of Interpersonal Violence, 22, 3, 292-311.

Swanberg, J., M. Ojha and C. Macke (2012),' State employment protection statutes for victims of domestic violence: public policy's response to domestic violence as an employment matter', Journal of Interpersonal Violence, 27, 3, 587-619

Tiesman, H., K. Gurka, S. Konda, J. Coben and H. Amandus (2012), 'Workplace homicides among U.S. women: The role of intimate partner violence', Annals of Epidemiology,

TUC (2002), Domestic Violence: A Guide for the Workplace. (TUC Publications: London)

TUC (2013), TUC Women's Conference Agenda 2013www.tuc.org

TUC (2014), Domestic Violence and the Workplace, TUC Survey Report (TUC)

USDAW (2016), Women's Equality: Domestic Abuse (Leaflet 416).

Wagner, K (2003), Joint labor/ management domestic violence awareness programme (Corporate Alliance to End Partner Violence).

Walby, S. (2009), The Cost of Domestic Violence: Update 2009. (Lancaster University).

Walby, S., J. Towers and B. Francis (2016), 'Is violent crime increasing or decreasing? A new methodology to measure repeat attacks making visible the significance of gender and domestic relations', British Journal of Criminology, 56, 6, 1203-1234. 
Walby, S. and J. Allen (2004), Domestic Violence, Sexual Assault and Stalking: Findings from the British Crime Survey, (Home Office).

Wathen, C., J. MacGregor and B. MacQuarrie (2016), 'Relationships Among Intimate Partner Violence, Work, and Health', Journal of Interpersonal Violence. Online early cite doi: $10.1177 / 0886260515624236$. 